\title{
Care programme approach: the experience in Bath
}

\author{
Maria Broughton and Paul Divall
}

The care programme approach was developed to ensure that patients in the community recelve the health and social care they need. If pre-empted the philosophy and practice of care management and can form the core. There are several strengths to this approach in that it permits a response to individual needs that may change over a period of time, and co-ordinates the contribution of all care agencies to make effective use of the available resources.

The care programme approach (CPA) was developed to ensure that patients in the community receive the health and social care they need. The 1989 White Paper Caring for People and the subsequent circular issued by the Department of Health (1990) required district health authorities "to implement the care programme approach for people with a mental illness, including dementia, whatever its cause, referred to the specialist psychiatric services". Local care programme policies were to be drawn up and implemented by 1 April 1991. It was recommended that all care programmes should include several key elements as follow.

\section{Key elements}

(a) People with mental health problems who could be, or who are being, treated in the community should have their health and social care needs fully assessed, including the support required by carers.

(b) An individual care programme should be drawn up to meet the assessed need rather than the availability of services. This should take account of the wishes of the patient and, as appropriate, the carers.

(c) A monitoring system should be in place to ensure that the required health and social care services in the care plan are provided. Individual care programmes should be monitored for effectiveness, and reviewed regularly. One named person should be appointed as the key worker to keep in close contact with the patient and to monitor that the agreed care is given.

\section{To whom should it apply?}

In the city of Bath, where care programmes have been implemented for the past year, a care programme is drawn up for patients meeting one or more of the following criteria:

(a) patients being considered for discharge who have been in a psychiatric hospital for more than six months, either continuously or cumulatively, during the preceding 12 months

(b) patients with serious mental illness whose health and social care needs require the attention of more than one agency

(c) patients being considered for discharge or already living in the community whose lives have been seriously disrupted as a result of mental illness and who would be vulnerable without a care programme.

It was decided that where the patient is under section 117 of the Mental Health Act 1983, the care programme would be in the form of a discharge or aftercare plan. A CPA would not be arranged for those patients whose needs would be covered by the discharge from hospital plan.

Using these criteria, in Bath the number of patients to whom the CPA has been applied is shown in Tables 1 and 2 . Team $A$ is the only team engaged solely in old age psychiatry; the others have general adult psychiatry as a major component of their service.

Table 1. Number of meetings held per team and the number of individuals subject to care programme meetings

\begin{tabular}{lll}
\hline Team & $\begin{array}{l}\text { Number of } \\
\text { meetings }\end{array}$ & $\begin{array}{l}\text { Number of } \\
\text { individuals }\end{array}$ \\
\hline Team A & 96 & 60 \\
Team B & 63 & 35 \\
Team C & 42 & 25 \\
Team D & 33 & 24 \\
\hline
\end{tabular}


Table 2. Number of times meetings were held for individuals subject to care programming

\begin{tabular}{lllllll}
\hline Team & \multicolumn{2}{l}{ Times meetings were held } & & $\begin{array}{c}\text { Number of } \\
\text { individuals }\end{array}$ \\
\cline { 2 - 6 } & $\times \mathbf{1}$ & $\times 2$ & $\times 3$ & $\times \mathbf{4}$ & $\mathbf{5}$ & \\
\hline Team A & 35 & 17 & 6 & 1 & 1 & 60 \\
Team B & 17 & 12 & 3 & 2 & 1 & 35 \\
Team C & 13 & 8 & 3 & 1 & 0 & 25 \\
Team D & 18 & 4 & 1 & 1 & 0 & 24 \\
\hline
\end{tabular}

\section{How should it be done?}

The decision whether there is a need for a care programme is taken once appropriate multiagency assessments of health and social needs have been made. If there is a need for a care programme, a key worker is agreed at the initial assessment meeting. Ideally, the key worker will be known to, and able to work with, both hospital and community based teams. The key worker acts as case co-ordinator and is responsible for convening the review care programme meetings.

One task of the initial care programme meeting is to identify a core group of people actively involved in the care of the patient. Services are identified that would meet the patient's health and social needs. The patient or the carer, or both, are invited to attend the meeting, but if the patient declines to attend his or her views are sought by the key worker prior to the meeting. After the meeting, the key worker needs to review the continuing programme with the patient and carer to ensure that they understand it, especially if the patient was unable to attend the meeting. Patients and carers are given an opportunity to sign the review form to signify ownership and involvement in it. A patient's general practitioner is often invited to these CPA meetings.

If the patient is too confused to contribute to an assessment review, then decisions are made in the patient's best interests by members of the multidisciplinary team and carers or relatives. If the patient refuses a particular service within the care programme, it is recorded on the assessment review form.

Each care programme meeting has an identified chairperson who is required to accept responsibility for the completion of the meeting record proforma. A date for a review meeting is either set at the previous meeting or convened when there has been a change of circumstances. It has been recommended that review meetings should be held as often as needed, but at least at six monthly or annual intervals for those patients whose situation is stable.

The availability of resources to meet all needs is assessed. If any are not available, senior health and social services managers are advised of the unmet needs due to service deficits and the care programme implemented as far as possible.

CPA meetings do not have to be held in the hospital where the patient was treated as an in-patient, but should be held in a mutually convenient place. However, if the initial CPA meeting involves an in-patient, it is preferable that the meeting takes place before discharge.

The care programme continues until review identifies no further need to continue and the patient or carer, or both, agree to cease contact with the service.

\section{Administration}

In Bath, a care programme administrator, who is based in the local social services department, acts as a contact point for case co-ordinators and others by dealing with the organisation and management of meetings. The administrator sends out the invitations and review reminders to those involved in the CPA, takes responsibility for distributing the reports and maintains a database on patients subject to the CPA.

\section{Comments}

The CPA has a narrower and less ambitious aim than care management. However, it pre-empted the philosophy and practice of care management and can form the core. Care management will be led by social services supported by a budget, whereas the CPA will be health led but there will be no specific financial resources allocated to care programming. It is anticipated that there will be identification from the CPA of a group of patients who would benefit from referral to care management services. Formal full case conferences will be reserved for the most complex care needs.

The care programme approach is used to permit a response to individual needs that may change over time, and to co-ordinate the contribution of all care agencies to maximise the benefits to patients. It is also useful in identifying deficiencies as a basis for future improvement 
and to make effective use of the avallable resources.

The benefits and outcomes of the care programme approach are being increasingly evaluated as the implementation of this approach grows throughout the country.

\section{Acknowledgement}

The authors would like to thank Gerald Ryan, Team Manager, Bath Social Services Department, for his help in the preparation of this paper.

\section{References}

Department of Health (1989) Caring for People: Community Care in the Next Decade and Beyond. London: HMSO.

- (1990) Health and Soctal Services Development, 'Caring for People'. The Care Programme Approach for People with a Mental Ilness Referred to the Specialist Psychlatric Services. Joint Health/Social Services circular: HC(90)23/LASSL90)11.

Maria Broughton, Senior Registrar in Old Age Psychiatry; and Paul Divall, Consultant in Old Age Psychiatry, St Martin's Hospital, Midford Road, Bath, BA2 5RP

\section{Defeat Depression Action Week}

\section{3-11 March 1994}

Aims

* to raise awareness about depression

* to reduce the stigma associated with it

* to give advice on seeking help

There will be a two mile fun run in Hyde Park, London, as part of the Defeat Depression
Action Week. This will start at 11 a.m. on Sunday, 6 March. The entry fee is $£ 3$ and the total amount received in entry fees will be matched by a commercial company and all proceeds will be donated to the Defeat Depression Campaign.

If you are interested in this event please contact Christine Gear on 0712352351. 